\title{
A study to assess the knowledge regarding post operative care amoqg primigravida mothers undergoing caesarean section \\ *Poongodi .V
}

\section{Abstract}

Objectives : To assess the level of knowledge regarding post operative care among primi gravida mothers undergoing caesarean section, Methods $\sim$ Descriptive research design was used for the study. Result: showed that out of 30 samples 13 (43.3\%) mothers had inadequate knowledge, 11 (36.6\%) mothers had moderately adequate knowledge and 06 (20\%) mothers had adequate knowledge. Conclusion: the Primi gravida post natal mothers need education regarding the post operative care after caesarean section.

Key Words: Primi gravida, cesarian section, post operative

\section{Introduction}

The caesarean section rate rise steadily from 16.6 to ,. 27.4 per 100 hospital deliveries, resulting in $65 \%$ increase over 12 years.3 Maternal deaths and complications from caesarean sections was high. Increased involvement of specialists in the care and improved intra and post operative management of cases was advocated to reduce the higher. maternal mortality rate.4 Limited maternity stay imposes a great chaUenge for the nurse about the post operative care after caesarean section. Thus the investigator feels that there, is a great need to provide the information on the post operative care after caesarean section to the primi gravida women4.

\section{Statement of the problem}

A study to assess the knowledge regarding post operative care among primi gravida mothers undergoingcaesarean section in selected hospital.

\section{Objectives}

- To assess the level of knowledge regarding post operative care among primi gravidae mothers undergoing caesarean section.

- To associate the level of knowledge with selected demographic variables.

\section{Research Methodology Research approach}

Quantitative research was used to assess the knowledge regarding postoperative care after caesarean section.

\section{Research design}

Descriptive research design was chosen for the study to assess theknowledge regarding post operativecare after caesarean section

\section{Sample size}

30 Primi gravida post natal mothers underwent caesarean section 


\section{Sampling technique}

Non probability convenient sampling technique.

\section{Criteria for sample selection Inclusion criteria}

- Primi gravida post natal mothers undeiwent caesarean section.

- Mothers available during data collection period.

- Mothers who were understand Tamil or English.

\section{Exclusion criteria}

- Primi gravida postnatal mothers undeiwent normal vaginal delivery.

- Women underwent other abdominal surgeries.

Data Analysis

Table: 1 frequency and percentage distribution of knowledge among the Primi gravida post natal mothers underwent caesarean section regarding the post operative care after caesarean section.

\begin{tabular}{|c|c|c|c|}
\hline S.No & $\begin{array}{c}\text { Level of } \\
\text { Knowledge }\end{array}$ & $\mathbf{F}$ & $\%$ \\
\hline 1 & $\begin{array}{c}\text { Inadequate } \\
\text { knowledge }\end{array}$ & 13 & $43.4 \%$ \\
\hline 2 & $\begin{array}{c}\text { Moderately } \\
\text { adequate } \\
\text { Knowledge }\end{array}$ & 06 & $36.6 \%$ \\
\hline 3 & $\begin{array}{c}\text { Adequate } \\
\text { knowledge }\end{array}$ & 13 & $20 \%$ \\
\hline
\end{tabular}

\section{Major findings}

With regard to age of mother $18(60 \%)$ were in the age group of 23 27 years, majority of mothers had second education, among 30 mothers $24(80 \%)$ were house wives '24(80\%) were have monthly income of Rs $\leq 3000,24(80 \%)$ mothers from nuclear family, $20(66.70 \%)$ belongs to Hindu religion, 22(73.3\%) mothers living in urban areas, majority: the mothers12( $40 \%$ ) were getting health information through health personnel.

With regards to the mothers knowledge regarding the post operative care after caesarean section, out of 30 samples 13( 43.4\%) mothers had inadequate knowledge, 11(36.6\%) mothers had moderately adequate knowledge, 06(20.0\%) mothers had adequate knowledge The association of the level of knowledge among the Primi gravida post natal mothers underwent caesarean section regarding the post operative care after caesarean section with selected demographic variables revealed that the age, education, occupation, family income, type of family, religion area of residence were significant at the level of $\mathrm{P}<0.05$.

\section{Limitations}

- The sample selection was limited to 30 samples.

- The data collection period of the study was one week.

\section{Conclusion}

The study concluded that majority of the mothers had inadequate knowledge and moderately adequate knowledge. This shows that knowledge regarding the post operative care after caesarean section was inadequate. There is a need to improve the knowledge regarding the post operative care after caesarean section. 


\section{References}

1. Statistics report on world health organization, regarding caesarean section. Wttp://does Google.com.

2. Sreevidya.S. Sathiyasekaran BW, population - based cross sectional study on high casearea rates in madras (India), 2003 Feb;110(2):106-11.PMID 12618152.
3. Bobak. Text book of maternal andgynecologic care. 4 th edition. Masbypublications. PP 1066.
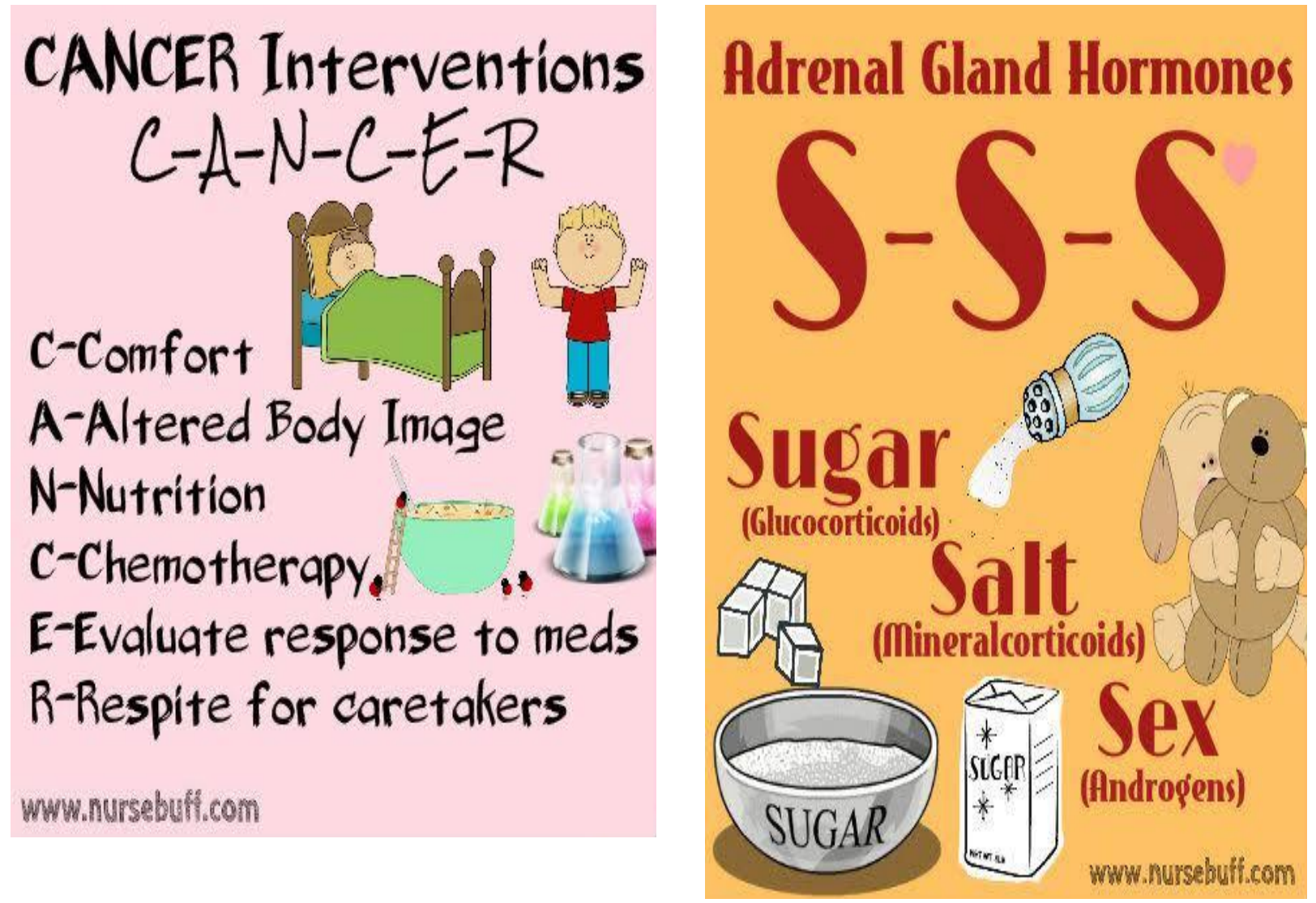